in vivo $35: 1091-1100(2021)$

doi:10.21873/invivo.12354

\title{
Prognostic Significance of the Immunological Indices in Patients Who Underwent Complete Resection of Pulmonary Metastases of Colorectal Cancer
}

\author{
YUKI OKAZAKI ${ }^{1}$, MASATSUNE SHIBUTANI ${ }^{1}$, EN WANG $^{1}$, HISASHI NAGAHARA ${ }^{1}$, \\ TATSUNARI FUKUOKA ${ }^{1}$, YASUHITO ISEKI ${ }^{1}$, SHINICHIRO KASHIWAGI $^{2}$, HIROAKI TANAKA $^{1}$, \\ KIYOSHI MAEDA ${ }^{1,3}$, KOSEI HIRAKAWA $^{1}$ and MASAICHI OHIRA ${ }^{1}$ \\ ${ }^{1}$ Department of Gastroenterological Surgery, Osaka City University Graduate School of Medicine, Osaka, Japan; \\ ${ }^{2}$ Department of Breast and Endocrine Surgery, Osaka City University Graduate School of Medicine, Osaka, Japan; \\ ${ }^{3}$ Department of Gastroenterological Surgery, Osaka City General Hospital, Osaka, Japan
}

\begin{abstract}
Background/Aim: The neutrophil-to-lymphocyte ratio (NLR) and the density of tumor-infiltrating lymphocytes (TILs) have been reported as immunological prognostic factors for various cancers. We evaluated the association between the prognosis and the immunological status in patients who underwent complete resection of pulmonary metastases of colorectal cancer (CRC). Patients and Methods: We evaluated the associations between the NLR before the resection of pulmonary metastases and the relapsefree survival (RFS) or overall survival (OS), or between the density of TILs in the pulmonary metastasis and the RFS or OS. Results: The RFS and OS were significantly worse in the NLR-High group than in the NLR-Low group. The RFS was significantly longer in the CD $3^{+}$TILs-High group than in the $C D 3^{+}$TILs-Low group. Conclusion: The NLR and the density of TILs may have prognostic significance in patients who undergo complete resection of pulmonary metastases of CRC.
\end{abstract}

Pulmonary metastasis occurs in 10\%-29\% of colorectal cancer (CRC) patients and is the second most common site of CRC metastasis, after hepatic metastasis (1-6). Surgical resection is widely accepted as the first-line therapy for pulmonary metastasis (7-10). It is currently considered

This article is freely accessible online.

Correspondence to: Masatsune Shibutani, Osaka City University Graduate School of Medicine, Department of Gastroenterological Surgery, 1-4-3 Asahi-machi Abeno-ku, Osaka City, Osaka Prefecture, 545-8585, Japan. Tel: +81 666453838, Fax: +81 666466450, e-mail: fbxbj429@ybb.ne.jp

Key Words: Neutrophil-to-lymphocyte ratio, tumor-infiltrating lymphocytes, pulmonary metastases of colorectal cancer. acceptable to resect pulmonary metastasis of CRC while maintaining an adequate pulmonary function, if complete treatment of the primary tumor as well as of all the other metastases have been achieved (7-10). However, the 5-year overall survival (OS) rate after resection of pulmonary metastases ranges from $30 \%$ to $68 \%$ according to reports $(11,12)$. Therefore, in order to determine the ideal treatment strategy of pulmonary metastases of CRC, the classification of patients by prognostic factors has been proposed (13-15).

The clinicopathological factors related to the prognosis after resection of pulmonary metastasis of CRC reportedly include the timing of metastasis (metachronous or synchronous) (16), number of metastases $(9,13)$, diameter of the metastasis (13), distribution of metastasis (ipsilateral or bilateral) (17), mediastinal lymph node involvement (9, 10, 18), carcinoembryonic antigen (CEA) levels before resection of pulmonary metastases $(10,13,18,19)$, primary $\mathrm{T} / \mathrm{N}$ classification as defined by the Union for International Cancer Control (UICC) $8^{\text {th }}(17,20)$, and disease-free interval after resection of primary tumor (18). However, the prognostic factors after pulmonary metastasis of CRC have not yet been confirmed.

On the other hand, the immunological status of the host has also been reported to affect the effectiveness of cancer treatment $(21,22)$. Similar to the primary tumor of CRC, in pulmonary metastasis of CRC, the prognosis may be significantly altered by not only tumor factors but also the immunological status of the host. The neutrophil-tolymphocyte ratio (NLR) as a systemic inflammatory marker (23-26) and the density of tumor-infiltrating lymphocytes (TILs), which reflects the immunological status in the tumor microenvironment $(27,28)$, have been reported as immunological prognostic factors for various cancers, including CRC. CRC is one of the few carcinomas with an 

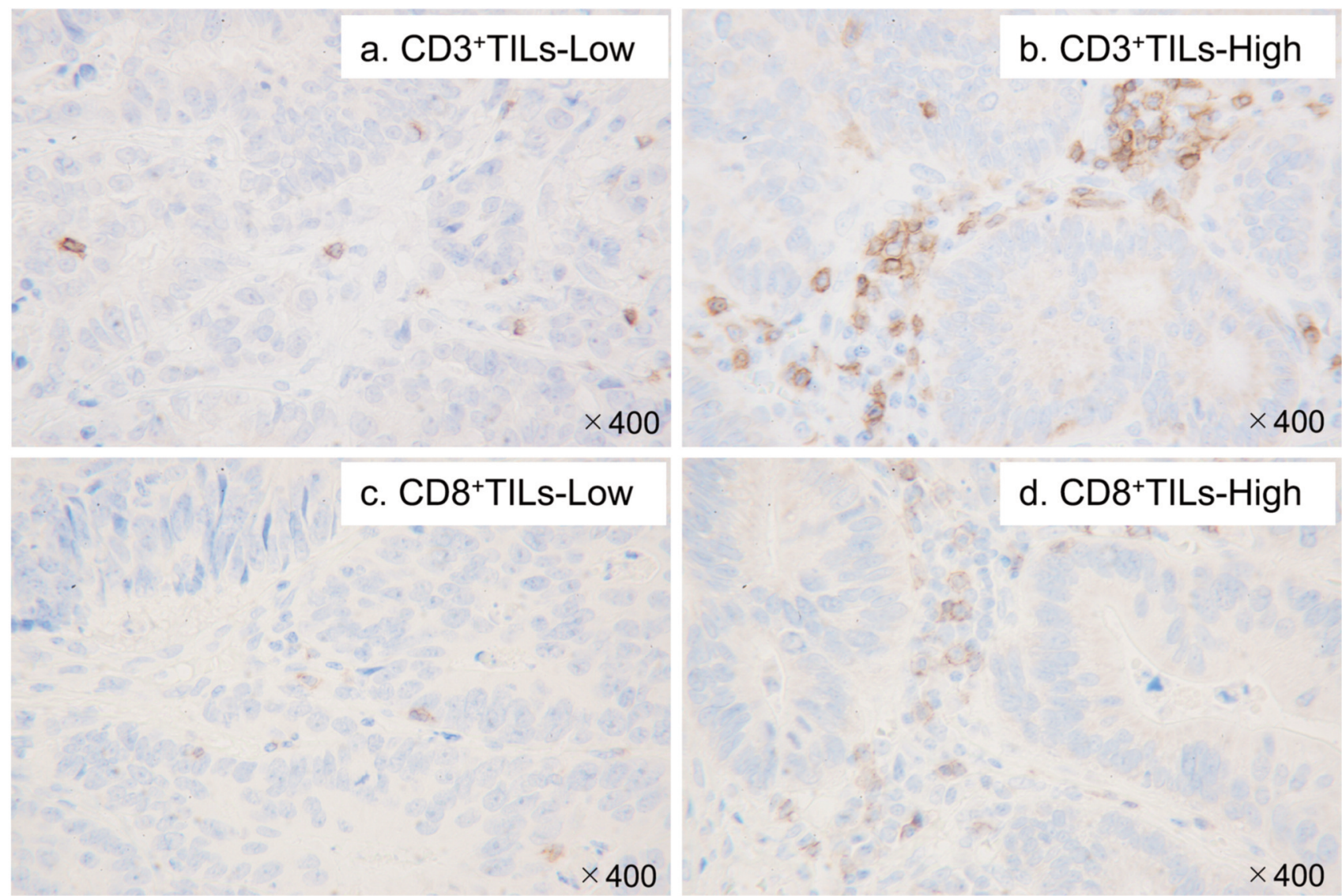

Figure 1. Tumor-infiltrating lymphocytes of pulmonary metastases of colorectal cancer. Immunohistochemical detection of the low (a) and high (b) presence of $\mathrm{CD}^{+}$tumor-infiltrating lymphocytes and the low $(c)$ and high $(d)$ presence of $C D 8^{+}$tumor-infiltrating lymphocytes.

established therapeutic strategy, which includes resection of distant metastasis. Thus, using the resected surgical specimen, we can examine the immunological status of the tumor microenvironment of pulmonary metastasis.

The present study evaluated the association between the prognosis of patients who underwent radical resection of pulmonary metastases of CRC and the immunological indices described above.

\section{Patients and Methods}

Patients. We retrospectively reviewed 17 patients who underwent potentially curative surgery for pulmonary metastases of CRC between January 1998 and December 2018 at Osaka City University. In this study, all primary tumors of CRC were resected radically, and all pulmonary resections that were performed were the first resections of pulmonary metastases of CRC. The 17 cases included patients who had either received chemotherapy or had undergone resection of hepatic metastasis before undergoing the resection of pulmonary metastasis. Pulmonary metastases detected at resection of the primary tumor were defined as synchronous metastases, while those detected after resection of the primary tumor were defined as metachronous metastases.
This retrospective study was approved by the Ethics Committee of Osaka City University (approval number: 3853, 4182) and conducted in accordance with the Declaration of Helsinki. All patients provided their written informed consent.

Methods. The associations between the clinicopathological factors and the relapse-free survival (RFS) or the overall survival (OS) were statistically evaluated. The clinicopathological factors were the primary $\mathrm{T} / \mathrm{N}$ classification as defined by the Union for International Cancer Control (UICC) $8^{\text {th }}(17,20)$, synchronous/metachronous metastasis, distribution of metastasis (ipsilateral or bilateral) (17), the number of metastases, the maximum diameter of metastasis, and the CEA level before resection of pulmonary metastasis. In this study, the RFS was defined as the interval between the date of the first complete pulmonary resection and the date of the diagnosis of the first recurrence, the date of death due to any cause, or the date of the last follow-up. The OS was defined as the interval between the date of the first complete pulmonary resection and the date of death due to any cause, or the date of the last follow-up.

To evaluate the correlation between the prognosis and systemic inflammation, the association between the NLR and RFS/OS after resection of pulmonary metastases of CRC was investigated. The NLR was calculated from a blood sample obtained within two 
Table I. Patient clinicopathological characteristics before the resection of the pulmonary metastases and association between NLR/TILs and the clinicopathological characteristics.

\begin{tabular}{|c|c|c|c|c|c|c|c|c|c|c|}
\hline $\begin{array}{l}\text { Patient characteristics } \\
\text { before pulmonary } \\
\text { resection }\end{array}$ & $(\mathrm{n}=17)$ & $\begin{array}{c}\mathrm{NLR}<2.5 \\
(\mathrm{n}=11)\end{array}$ & $\begin{array}{c}\mathrm{NLR} \geq 2.5 \\
\quad(\mathrm{n}=6)\end{array}$ & $p$-Value & $\begin{array}{c}\mathrm{CD} 3<31 \\
(\mathrm{n}=10)\end{array}$ & $\begin{array}{c}\mathrm{CD} 3 \geq 31 \\
(\mathrm{n}=7)\end{array}$ & $p$-Value & $\begin{array}{c}\text { CD8<21 } \\
(n=12)\end{array}$ & $\begin{array}{c}\mathrm{CD} 8 \geq 21 \\
(\mathrm{n}=5)\end{array}$ & $p$-Value \\
\hline \multicolumn{11}{|l|}{ Gender, n (\%) } \\
\hline Male & $8(47.1 \%)$ & $8(72.7 \%)$ & $1(16.7 \%)$ & \multirow[t]{2}{*}{0.049} & $5(50.0 \%)$ & $4(57.1 \%)$ & \multirow[t]{2}{*}{$>0.999$} & $7(58.3 \%)$ & $2(40.0 \%)$ & \multirow[t]{2}{*}{0.620} \\
\hline Female & $9(52.9 \%)$ & $3(27.3 \%)$ & $5(83.3 \%)$ & & $5(50.0 \%)$ & $3(42.9 \%)$ & & $5(41.7 \%)$ & $3(60.0 \%)$ & \\
\hline $\begin{array}{l}\text { Age, median } \\
\text { (range) years }\end{array}$ & $72(57-84)$ & $65(57-79)$ & $75(61-84)$ & 0.119 & $72.5(57-84)$ & $71(60-79)$ & 0.884 & $68(57-84)$ & $74(60-79)$ & 0.399 \\
\hline \multicolumn{11}{|l|}{$\begin{array}{l}\text { Location of primary } \\
\text { tumor, } \mathrm{n}(\%)\end{array}$} \\
\hline Right & $3(17.6 \%)$ & $3(27.3 \%)$ & $0(0 \%)$ & \multirow[t]{2}{*}{0.515} & $1(10.0 \%)$ & $2(28.6 \%)$ & \multirow[t]{2}{*}{0.537} & $2(16.7 \%)$ & $1(20.0 \%)$ & \multirow[t]{2}{*}{$>0.999$} \\
\hline Left & $14(82.4 \%)$ & $8(72.7 \%)$ & $6(100 \%)$ & & $9(90.0 \%)$ & $5(71.4 \%)$ & & $10(83.3 \%)$ & $4(80.0 \%)$ & \\
\hline \multicolumn{11}{|l|}{ Primary $\mathrm{T}$ status, $\mathrm{n}(\%)$} \\
\hline$\leq \mathrm{T} 3$ & $12(70.6 \%)$ & $8(72.7 \%)$ & $4(66.7 \%)$ & \multirow[t]{2}{*}{0.793} & $7(70.0 \%)$ & $5(71.4 \%)$ & \multirow[t]{2}{*}{$>0.999$} & $8(66.7 \%)$ & $4(80.0 \%)$ & \multirow[t]{2}{*}{$>0.999$} \\
\hline $\mathrm{T} 4$ & $5(29.4 \%)$ & $3(27.3 \%)$ & $2(33.3 \%)$ & & $3(30.0 \%)$ & $2(28.6 \%)$ & & $4(33.3 \%)$ & $1(20.0 \%)$ & \\
\hline \multicolumn{11}{|c|}{ Primary N status, $\mathrm{n}(\%)$} \\
\hline No & $7(41.2 \%)$ & $7(63.6 \%)$ & $0(0 \%)$ & \multirow[t]{2}{*}{0.035} & $2(30.0 \%)$ & $5(71.4 \%)$ & \multirow[t]{2}{*}{0.058} & $4(33.3 \%)$ & $3(60.0 \%)$ & \multirow[t]{2}{*}{0.593} \\
\hline$\geq \mathrm{N} 1$ & $10(58.8 \%)$ & $4(36.4 \%)$ & $6(100 \%)$ & & $8(80.0 \%)$ & $2(28.6 \%)$ & & $8(66.7 \%)$ & $2(40.0 \%)$ & \\
\hline \multicolumn{11}{|l|}{$\begin{array}{l}\text { Histological type of } \\
\text { primary tumor, } \mathrm{n}(\%)\end{array}$} \\
\hline Well, moderately diff. & $17(100 \%)$ & $11(100 \%)$ & $6(100 \%)$ & \multirow[t]{2}{*}{ - } & $10(100 \%)$ & $7(100 \%)$ & \multirow[t]{2}{*}{-} & $12(100 \%)$ & $5(100 \%)$ & \multirow[t]{2}{*}{-} \\
\hline Poorly diff. mucinous & $0(0 \%)$ & $0(0 \%)$ & $0(0 \%)$ & & $0(0 \%)$ & $0(0 \%)$ & & $0(0 \%)$ & $0(0 \%)$ & \\
\hline \multicolumn{11}{|l|}{$\begin{array}{l}\text { Detection of pulmonary } \\
\text { metastases, } \mathrm{n}(\%)\end{array}$} \\
\hline Metachronous & $10(58.8 \%)$ & $7(63.6 \%)$ & $3(50.0 \%)$ & \multirow[t]{2}{*}{0.644} & $6(60.0 \%)$ & $4(57.1 \%)$ & \multirow[t]{2}{*}{$>0.999$} & $8(66.7 \%)$ & $2(40.0 \%)$ & \multirow[t]{2}{*}{0.593} \\
\hline Synchronous & $7(41.2 \%)$ & $4(36.4 \%)$ & $3(50.0 \%)$ & & $4(40.0 \%)$ & $3(42.9 \%)$ & & $4(33.3 \%)$ & $3(60.0 \%)$ & \\
\hline \multicolumn{11}{|l|}{$\begin{array}{l}\text { Location of pulmonary } \\
\text { metastases, } \mathrm{n}(\%)\end{array}$} \\
\hline One lung field & $16(94.1 \%)$ & $11(100 \%)$ & $5(83.3 \%)$ & \multirow[t]{2}{*}{0.353} & $9(90.0 \%)$ & $7(100 \%)$ & $>0.999$ & $11(91.7 \%)$ & $5(100 \%)$ & $>0.999$ \\
\hline Both lung fields & $1(5.9 \%)$ & $0(0 \%)$ & $1(16.7 \%)$ & & $1(10.0 \%)$ & $0(0 \%)$ & & $1(8.3 \%)$ & $0(0 \%)$ & \\
\hline $\begin{array}{l}\text { Number of pulmonary } \\
\text { metastases, } \mathrm{n}(\%)\end{array}$ & & & & & & & & & & \\
\hline 1 & $11(64.7 \%)$ & $8(72.7 \%)$ & $3(50.0 \%)$ & 0.600 & $5(50.0 \%)$ & $6(85.7 \%)$ & 0.304 & $6(50.0 \%)$ & $5(100 \%)$ & 0.102 \\
\hline$\geq 2$ & $6(35.3 \%)$ & $3(27.3 \%)$ & $3(50.0 \%)$ & & $5(50.0 \%)$ & $1(14.3 \%)$ & & $6(50.0 \%)$ & $0(0 \%)$ & \\
\hline $\begin{array}{l}\text { Maximum diameter } \\
\text { of pulmonary } \\
\text { metastases, } \mathrm{n}(\%)\end{array}$ & & & & & & & & & & \\
\hline$<20 \mathrm{~mm}$ & $11(64.7 \%)$ & $9(81.8 \%)$ & $2(33.3 \%)$ & 0.109 & $7(70.0 \%)$ & $4(57.1 \%)$ & 0.644 & $8(66.7 \%)$ & $3(60.0 \%)$ & $>0.999$ \\
\hline$\geq 20 \mathrm{~mm}$ & $6(35.3 \%)$ & $2(18.2 \%)$ & $4(66.7 \%)$ & & $3(30.0 \%)$ & $3(42.9 \%)$ & & $4(33.3 \%)$ & $2(40.0 \%)$ & \\
\hline $\begin{array}{l}\text { Method of metasectomy, } \\
\mathrm{n}(\%)\end{array}$ & & & & & & & & & & \\
\hline Segmentectomy & $16(94.1 \%)$ & $11(100 \%)$ & $4(33.3 \%)$ & 0.110 & $9(90.0 \%)$ & $6(85.7 \%)$ & $>0.999$ & $11(91.7 \%)$ & $4(80.0 \%)$ & 0.515 \\
\hline Lobectomy & $1(5.9 \%)$ & $0(0 \%)$ & $2(66.7 \%)$ & & $1(10.0 \%)$ & $1(14.3 \%)$ & & $1(8.3 \%)$ & $1(20.0 \%)$ & \\
\hline $\begin{array}{l}\text { CEA level before } \\
\text { resection of } \\
\text { pulmonary metastases, } \\
\mathrm{n}(\%)\end{array}$ & & & & & & & & & & \\
\hline$\leq 5 \mathrm{ng} / \mathrm{ml}$ & $12(70.6 \%)$ & $9(81.8 \%)$ & $3(50.0 \%)$ & 0.280 & $6(60.0 \%)$ & $6(85.7 \%)$ & 0.338 & $8(66.7 \%)$ & $4(80.0 \%)$ & $>0.999$ \\
\hline$>5 \mathrm{ng} / \mathrm{ml}$ & $5(29.4 \%)$ & $2(18.2 \%)$ & $3(50.0 \%)$ & & $4(40.0 \%)$ & $1(14.3 \%)$ & & $4(33.3 \%)$ & $1(20.0 \%)$ & \\
\hline
\end{tabular}

NLR: Neutrophil to lymphocyte ratio; CEA: carcinoembryonic antigen.

weeks before pulmonary resection by dividing the absolute neutrophil count by the absolute lymphocyte count. To determine the appropriate cut-off value, we used a receiver operating characteristic (ROC) curve analysis. Based on the cut-off value, patients were classified into the NLR-High or NLR-Low groups.
The RFS or OS after resection of pulmonary metastasis was compared between the NLR-High and NLR-Low groups.

The immunological status in the tumor microenvironment was evaluated based on the association between the density of TILs in the specimen of the pulmonary metastasis and the prognosis after resection 


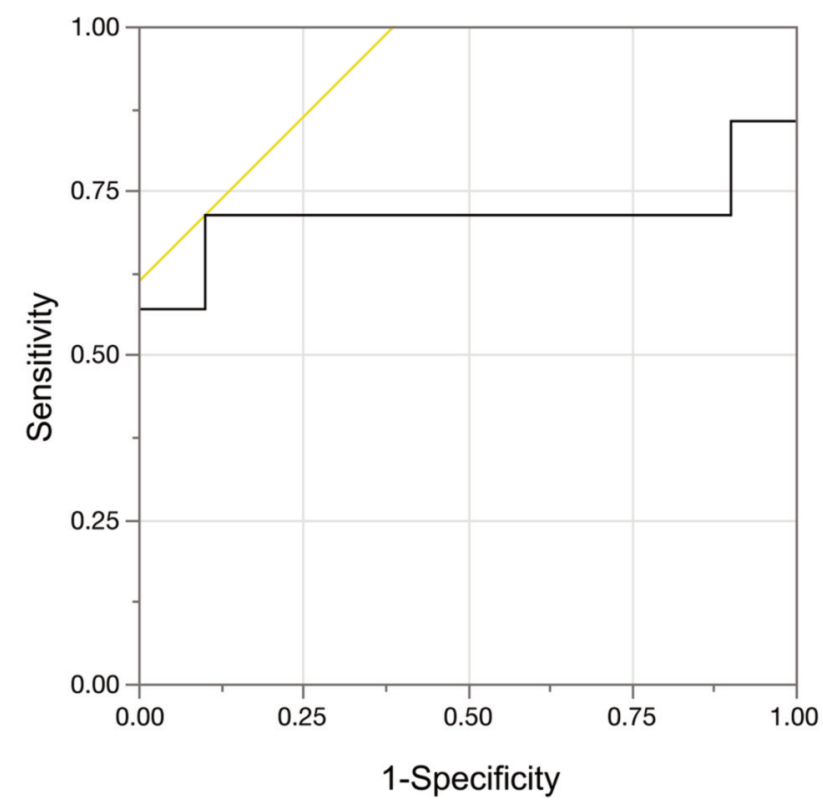

Figure 2. Receiver operating characteristic curve of the neutrophil-tolymphocyte ratio for the overall survival status. Area under the curve $=0.714 ; 95 \%$ confidence interval $=0.320-0.930 ; p=0.038$.

of pulmonary metastasis. Setting CD3 as the pan-T cell marker and CD8 as the cytotoxic T cell marker, the TILs of the pulmonary metastatic tumor sample were examined with immunohistochemical staining by anti-CD3 antibody and anti-CD8 antibody (CD3: Monoclonal Mouse Anti-Human CD3 CloneF7.2.38, 1:200 dilution; Dako, Glostup, Denmark; CD8: Monoclonal Mouse Anti-Human CD8 Clone C8/144B M7103, 1:200 dilution; Dako). The number of CD3 ${ }^{+}$TILs and $\mathrm{CD} 8^{+}$TILs at the invasive margin of the tumor was counted in 5 randomly selected fields at a magnification of $\times 400$, and the mean of the values obtained was used (Figure 1). The cut-off value was determined using the ROC curve analysis. Based on this cut-off value, patients were classified into the TILs-High or TILs-Low groups. The RFS or OS after resection of pulmonary metastasis was compared between the TILs-High and TILs-Low groups.

Statistical analyses. All statistical analyses were performed using the JMP software program, ver. 14.2.0 (SAS Institute, Japan, Tokyo). Fisher's exact test was used to analyze the association between each high and low group. Survival curves were made using the Kaplan-Meier method. Differences in the RFS or OS were assessed using the log-rank test. A multivariate analysis of the clinicopathological factors that were correlated with the survival was performed using a Cox proportional hazards model. Factors with a $p$-value of $<0.1$ on the univariate analysis were included as a covariate in the multivariate analysis. A $p$-value of $<0.05$ was considered to indicate a statistically significant difference.

\section{Results}

Patient characteristics. The 17 patients' characteristics are summarized in Table I. The study cohort included 8 males and 9 females, with a median age of 72 years old (range $=57$ -
84 years old). The primary tumor site was located on the right in 3 patients (from the cecum to transverse colon) and on the left in 14 patients (from the descending colon to rectum). The $\mathrm{T}$ factor was $\leq \mathrm{T} 3$ in 12 patients and $\mathrm{T} 4$ in 5 patients. The $\mathrm{N}$ factor was $\mathrm{N} 0$ in 7 patients and $\geq \mathrm{N} 1$ in 10 patients. The histological type of all patients was well- or moderatelydifferentiated adenocarcinoma. Ten patients had synchronous pulmonary metastasis, and seven had metachronous pulmonary metastasis. Eleven had only one lesion of pulmonary metastasis, and six patients had more than two lesions. Sixteen patients had pulmonary metastasis in one lung field, and one patient had pulmonary metastasis in both lung fields. The maximum diameter of pulmonary metastasis was $<20 \mathrm{~mm}$ in 11 patients and $\geq 20 \mathrm{~mm}$ in 6 patients. The CEA level within 2 weeks before resection of pulmonary metastasis was $\leq 5 \mathrm{ng} / \mathrm{ml}$ in 12 patients and $>5 \mathrm{ng} / \mathrm{ml}$ in 5 patients. Eight patients were treated with pulmonary resection alone, and nine patients were treated with pulmonary resection and postoperative adjuvant chemotherapy.

The survival rate after complete resection of pulmonary metastases of CRC. In this study, twelve patients (70.6\%) had recurrence, and the 5-year RFS rate after complete resection of pulmonary metastases of CRC was $22.6 \%$. Seven mortality events $(41.2 \%)$ occurred after complete resection of pulmonary metastases of CRC. The 5-year OS rate after complete resection of pulmonary metastases of CRC was $54.5 \%$.

The association between the NLR and the RFS/OS. We used the NLR, which was a continuous variable, as the test variable and the occurrence of all-cause mortality as the state variable. When we investigated the cut-off value for the NLR using the ROC curve, we found that the appropriate cut-off value for the NLR was 2.5 (sensitivity of $71.4 \%$; specificity of $90.0 \%$ ) (Figure 2). We therefore set that value as the cut-off, and the patients were then classified into high and low groups.

Eleven patients were in the NLR-Low group, and six were in the NLR-High group. Regarding the patients' characteristics before resection of pulmonary metastasis, a high NLR was significantly correlated with the lymph node metastasis of the primary tumor $(p=0.035)$. However, no significant differences in any other characteristics were found between the NLR-Low and NLR-High groups (Table 1). The RFS and OS after resection of pulmonary metastasis were significantly worse in the NLR-High group than in the NLR-Low group ( $p=0.001$, $p=0.003$, respectively) (Figure $3 \mathrm{a}$ and $\mathrm{b}$ ).

The association between the density of TILs and the RFS/OS. We used the number of positive TILs, which was a continuous variable, as the test variable and the occurrence of all-cause mortality as the state variable. When we investigated the cut-off value for the number of positive TILs using the ROC curve, we found that the appropriate cut-off 
A

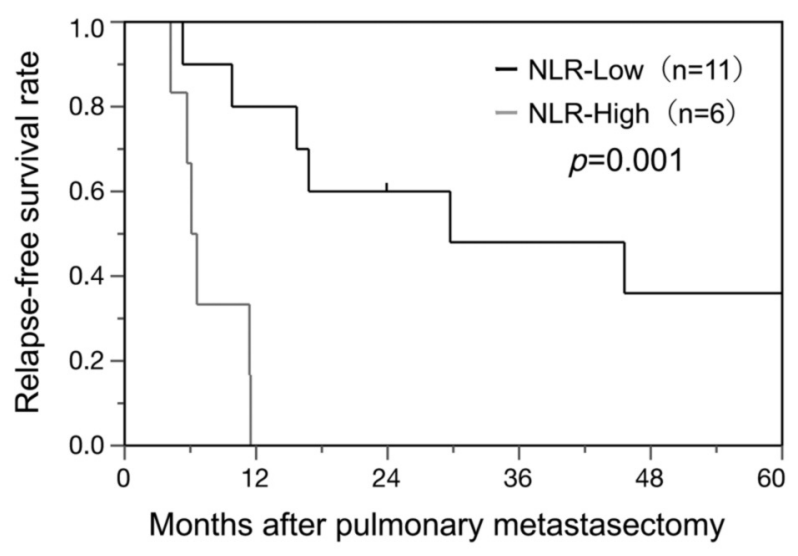

B

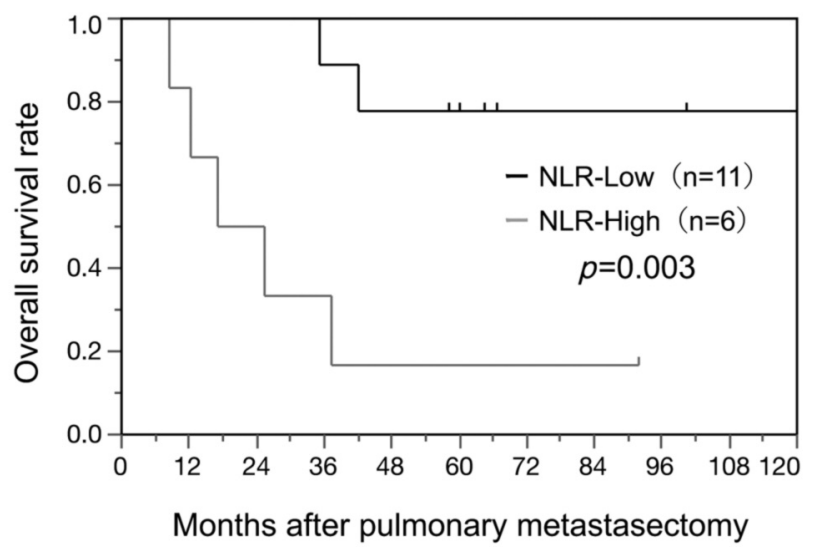

Figure 3. The association between the neutrophil-to-lymphocyte ratio and the survival status. (a) The association between the neutrophil-tolymphocyte ratio and the relapse-free survival after resection of pulmonary metastases. (b) The association between the neutrophil-to-lymphocyte ratio and the overall survival after resection of pulmonary metastases.

A

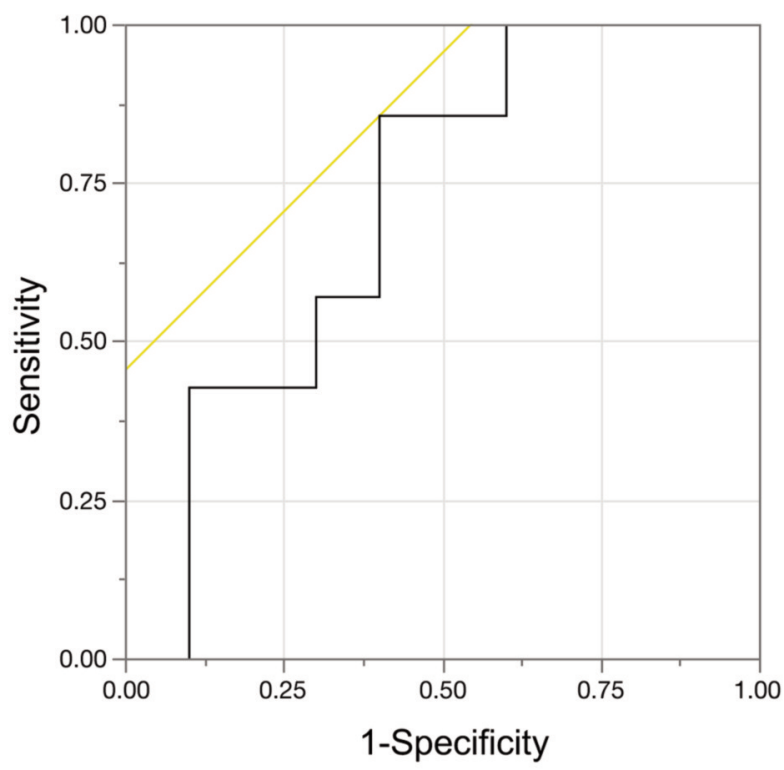

B

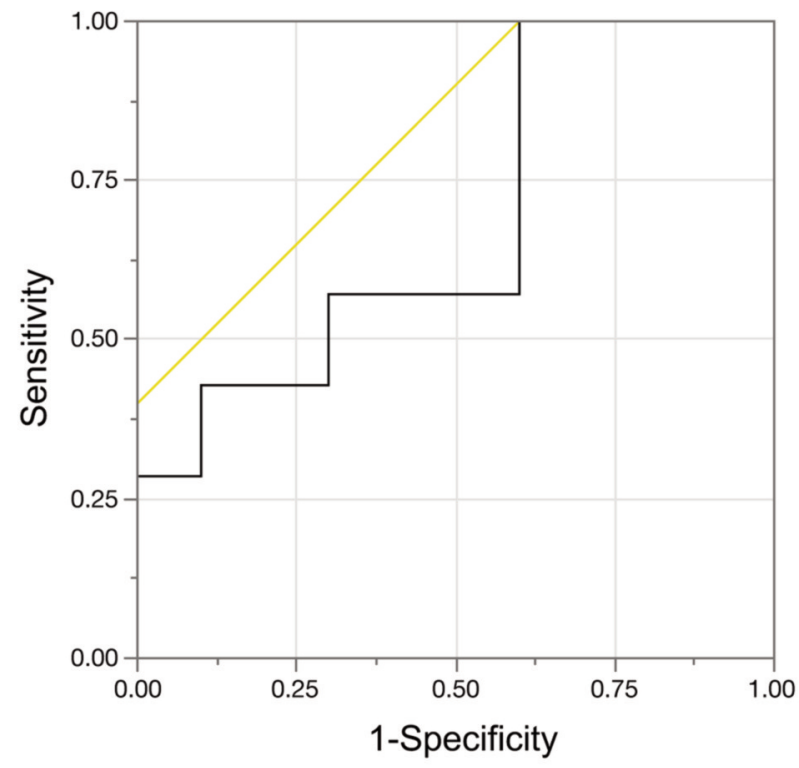

Figure 4. Receiver operating characteristic curve of the number of tumor-infiltrating lymphocytes for the overall survival status. (a) The overall survival status and CD3+ tumor-infiltrating lymphocytes. Area under the curve=0.714; 95\% confidence interval=0.415-0.898; $p=0.109$. (b) The overall survival status and CD8+ tumor-infiltrating lymphocytes. Area under the curve $=0.686 ; 95 \%$ confidence interval=0.378-0.887; $p=0.240$.

value for the $\mathrm{CD}^{+} \mathrm{TILs}$ was 31 (sensitivity of $85.7 \%$; specificity of $50.0 \%$ ) (Figure $4 a$ ). Using the ROC curve in the same manner, we set the cut-off value for the CD8 ${ }^{+} \mathrm{TILs}$ at 21 (sensitivity of $100.0 \%$; specificity of $40.0 \%$ ) (Figure $4 \mathrm{~b}$ ). We therefore set each value as the cut-off value, and the patients were then classified into high and low groups.
Seven patients were in the $\mathrm{CD}^{+}{ }^{+}$TILs-High group, and 10 were in the $\mathrm{CD} 3^{+}$TILs-Low group. No significant differences were found between the CD3 ${ }^{+}$TILs-Low and CD3 ${ }^{+}$TILsHigh groups in the patient's characteristics before resection of pulmonary metastasis (Table 1). The RFS after resection of pulmonary metastases was significantly longer in the 

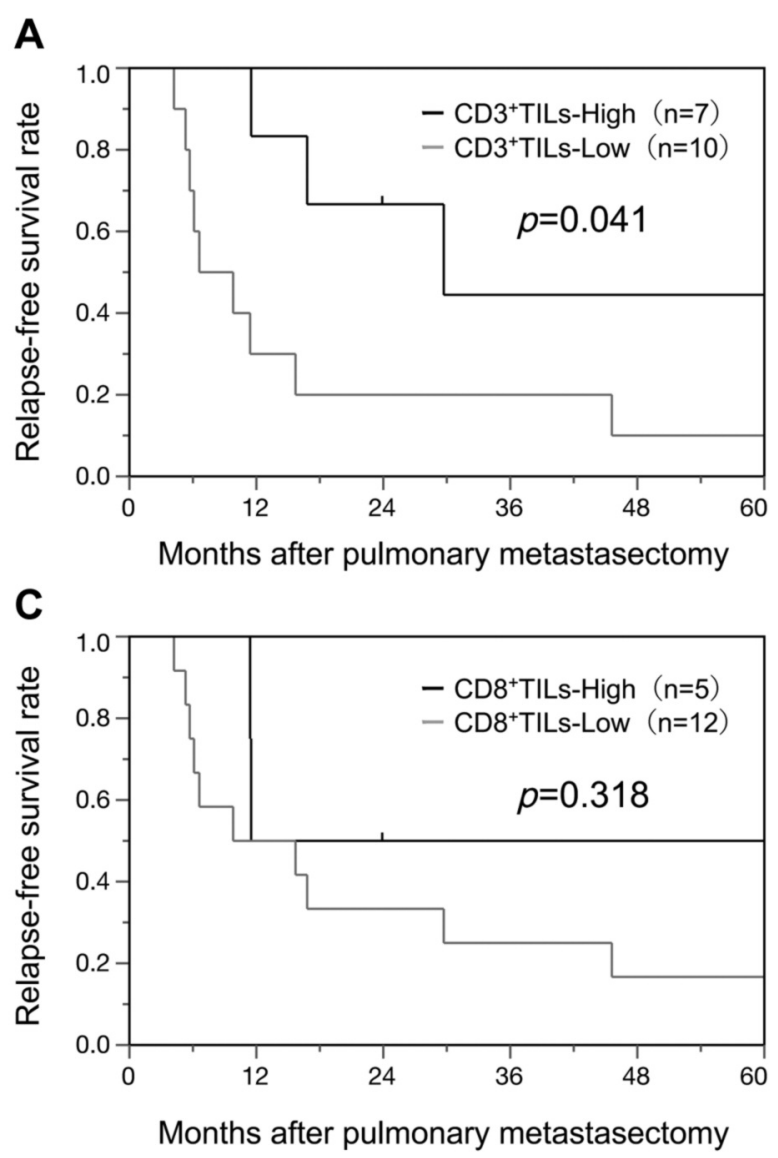

B
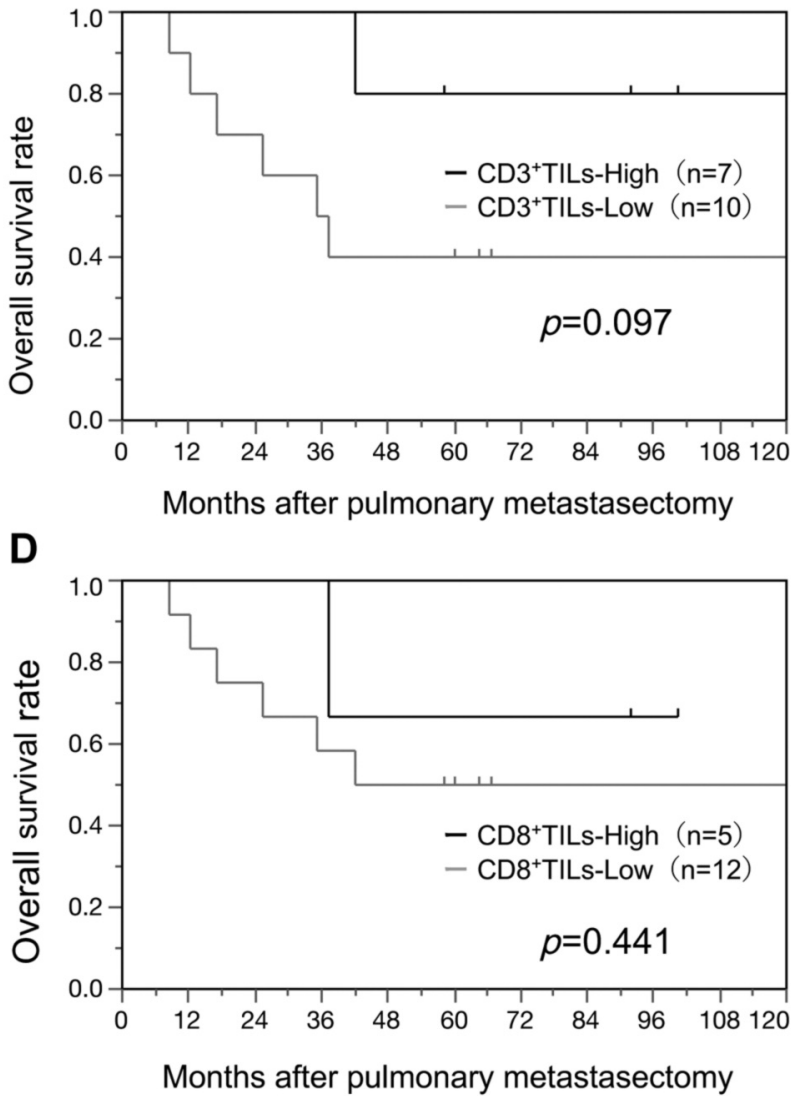

Figure 5. The association between tumor-infiltrating lymphocytes and the relapse-free and overall survival. (a) The association between CD3 ${ }^{+}$ tumor-infiltrating lymphocytes and the relapse-free survival after resection of pulmonary metastases. (b) The association between CD $3^{+}$tumorinfiltrating lymphocytes and the overall survival after resection of pulmonary metastases. (c) The association between CD ${ }^{+}$tumor-infiltrating lymphocytes and the relapse-free survival after resection of pulmonary metastases. (d) The association between CD ${ }^{+}$tumor-infiltrating lymphocytes and the overall survival after resection of pulmonary metastases.

CD $3^{+}$TILs-High group than in the $\mathrm{CD} 3^{+}$TILs-Low group $(p=0.041)$ (Figure 5a). The OS after resection of pulmonary metastases tended to be longer in the $\mathrm{CD} 3^{+}$TILs-High group than in the CD $3^{+}$TILs-Low group $(p=0.097)$ (Figure $5 \mathrm{~b}$ ).

Five patients were in the CD ${ }^{+}$TILs-High group and 12 were in the $\mathrm{CD}^{+}{ }^{+}$TILs-Low group. No significant differences were found between the CD8 ${ }^{+}$TILs-Low and CD $8^{+}$TILs-High groups in the patient's characteristics before resection of pulmonary metastasis (Table 1). Furthermore, no significant differences in the RFS/OS were found between the CD8 ${ }^{+}$TILs-Low and $\mathrm{CD} 8^{+}$TILs-High groups (Figure $5 \mathrm{c}$ and $\mathrm{d}$ ).

The evaluation of the prognostic factors for the RFS/OS. In the univariate analysis, the RFS after resection of pulmonary metastases was significantly shorter in the group with $\geq 2$ pulmonary metastases, the NLR-High group and the CD ${ }^{+}$TILs-Low group than the corresponding reference groups ( $p=0.013, p=0.025, p=0.038$, respectively) (Table II). In the multivariate analysis, the number of pulmonary metastases and the NLR before resection of pulmonary metastasis were found to be independent prognostic factors of the RFS ( $p=0.007, p=0.002$, respectively) (Table II). Furthermore, in the univariate analysis, the OS after resection of pulmonary metastases was significantly shorter in the NLR-High group than in the NLR-Low group $(p=0.008)$, and the OS after resection of pulmonary metastases tended to be shorter in the $\mathrm{CD}^{+}{ }^{+}$TILs-Low group than in the $\mathrm{CD}^{+}$TILs-High group $(p=0.077)$ (Table III). In the multivariate analysis, the NLR before resection of pulmonary metastasis was the only independent prognostic factor of the OS $(p=0.009)$ (Table 111). 
Okazaki et al: Immunological Indices in Patients Who Underwent Complete Resection of Pulmonary Metastases of CRC

Table II. Univariate and multivariate analysis of relapse-free survival after resection of pulmonary metastases.

\begin{tabular}{|c|c|c|c|c|c|c|}
\hline \multirow[b]{2}{*}{ Predictor } & \multicolumn{3}{|c|}{ Univariate analysis } & \multicolumn{3}{|c|}{ Multivariate analysis } \\
\hline & HR & $95 \% \mathrm{CI}$ & $p$-Value & HR & $95 \% \mathrm{CI}$ & $p$-Value \\
\hline $\begin{array}{l}\text { Detection of pulmonary metastases } \\
\text { (Metachronous } v s \text {. Synchronous) }\end{array}$ & 0.581 & $0.155-1.856$ & 0.366 & & & \\
\hline $\begin{array}{l}\text { Number of pulmonary metastases } \\
(1 v s . \geq 2)\end{array}$ & 5.082 & $1.423-20.20$ & 0.013 & 8.494 & $1.786-61.64$ & 0.007 \\
\hline $\begin{array}{l}\text { Maximum diameter of pulmonary metastases } \\
(<20 \mathrm{~mm} v s . \geq 20 \mathrm{~mm})\end{array}$ & 1.341 & $0.394-4.241$ & 0.622 & & & \\
\hline $\begin{array}{l}\text { CEA level before resection of pulmonary metastases } \\
(<5 \mathrm{ng} / \mathrm{ml} v s . \geq 5 \mathrm{ng} / \mathrm{ml})\end{array}$ & 1.309 & $0.348-4.183$ & 0.667 & & & \\
\hline $\begin{array}{l}\text { NLR before resection of pulmonary metastases } \\
(<2.5 v s . \geq 2.5)\end{array}$ & 5.987 & $1.262-31.75$ & 0.025 & 17.66 & $2.703-208.5$ & 0.002 \\
\hline $\begin{array}{l}\text { Number of } \mathrm{CD}^{+}{ }^{+} \mathrm{TILs} \\
(\geq 31 \mathrm{vs} .<31)\end{array}$ & 3.667 & $1.068-16.79$ & 0.038 & 2.759 & $0.676-14.17$ & 0.160 \\
\hline
\end{tabular}

HR: Hazard ratio; CI: confidence interval; CEA: carcinoembryonic antigen; NLR: neutrophil to lymphocyte ratio; TILs: tumor-infiltrating lymphocytes.

Table III. Univariate and multivariate analysis of overall survival after resection of pulmonary metastases.

\begin{tabular}{|c|c|c|c|c|c|c|}
\hline \multirow[b]{2}{*}{ Predictor } & \multicolumn{3}{|c|}{ Univariate analysis } & \multicolumn{3}{|c|}{ Multivariate analysis } \\
\hline & HR & $95 \% \mathrm{CI}$ & $p$-Value & HR & $95 \% \mathrm{CI}$ & $p$-Value \\
\hline $\begin{array}{l}\text { Detection of pulmonary metastases } \\
\text { (Metachronous } v s . \text { Synchronous) }\end{array}$ & 0.494 & $0.071-2.300$ & 0.381 & & & \\
\hline $\begin{array}{l}\text { Number of pulmonary metastases } \\
(1 v s . \geq 2)\end{array}$ & 3.417 & $0.743-17.56$ & 0.111 & & & \\
\hline $\begin{array}{l}\text { Maximum diameter of pulmonary metastases } \\
(<20 \mathrm{~mm} v s . \geq 20 \mathrm{~mm})\end{array}$ & 2.573 & $0.565-13.11$ & 0.216 & & & \\
\hline $\begin{array}{l}\text { CEA level before resection of pulmonary metastases } \\
(<5 \mathrm{ng} / \mathrm{m} l v s . \geq 5 \mathrm{ng} / \mathrm{ml})\end{array}$ & 2.148 & $0.421-9.802$ & 0.333 & & & \\
\hline $\begin{array}{l}\text { NLR before resection of pulmonary metastases } \\
(<2.5 v s . \geq 2.5)\end{array}$ & 8.590 & $1.772-61.82$ & 0.008 & 9.346 & $1.721-81.87$ & 0.009 \\
\hline $\begin{array}{l}\text { Number of CD } 3+\text { TILs } \\
(\geq 31 \text { vs. }<31)\end{array}$ & 5.065 & $0.857-96.01$ & 0.077 & 5.180 & $0.777-106.7$ & 0.095 \\
\hline
\end{tabular}

HR: Hazard ratio; CI: confidence interval; CEA: carcinoembryonic antigen; NLR: neutrophil to lymphocyte ratio; TILs: tumor-infiltrating lymphocytes.

\section{Discussion}

In recent years, advances in treatment, such as metastasectomy or systemic chemotherapy, have improved the prognosis of patients with distant metastasis of CRC. However, the mortality and recurrence rates can be improved further. The identification of patients who can most benefit from each treatment is therefore necessary, and to this end, various biomarkers have been reported as the prognostic predictors $(13,14,29)$.

The systemic inflammatory response has been recognized as being associated with the tumor progression. Thus, the association between systemic inflammatory markers and the clinical outcome has been reported in various types of cancer, including CRC (23-26). Neutrophils play an important role in tumor growth, invasion, and metastasis. Thus, an increase in the neutrophil count has been considered to reflect the progression of cancer (30). In contrast, lymphocytes play an important role in anti-tumor immunity and are related to the immune system of the host. A decrease in lymphocytes reportedly reflects the deterioration of the anti-tumor immunity and is associated with a poor prognosis (31). Thus, a high NLR means that the status of the host is favorable for cancer progression, suggesting that the NLR is a useful prognostic predictive biomarker (32). 
The association between the prognosis and the NLR in CRC patients has often been reported $(23,24,33,34)$. We have previously found that the preoperative NLR was a predictor of a poor prognosis after radical resection for CRC (35) and that the NLR was a prognostic predictor in patients with stage IV CRC who underwent palliative resection of asymptomatic primary tumor (29). Thus, the NLR appears to be useful for determining the prognosis of patients with radical resection of pulmonary metastases of CRC.

In the present study, patients with a high NLR before resection of pulmonary metastasis had a poor prognosis. Therefore, regarding patients with pulmonary metastasis of $\mathrm{CRC}$, our findings suggested that clarifying the systemic inflammation status by sampling preoperative blood might be an easy and useful method for predicting the prognosis after the resection of pulmonary metastases.

On the other hand, the presence of immune cells in the tumor microenvironment is considered to be related to the progression of cancer. Indeed, the density of TILs, which reflects the anti-tumor immune status of the host, has been reported to be a useful biomarker for predicting the therapeutic outcome or prognosis $(27,28)$. In CRC in particular, the density of CD8 ${ }^{+}$TILs and total T-lymphocytes is correlated with the anti-tumor immune status of the host, and these values are components of the 'Immunoscore', which is an immunological biomarker in CRC $(36,37)$.

The density of TILs in the primary tumor has often been reported to be a useful predictor of the therapeutic outcome; however, relatively few reports on the density of TILs in metastatic tumor have been published compared to reports on the density of TILs in primary tumor. In general, resection of metastatic tumors is rare, and the evaluation of the local immune status in metastatic tumor is not easy. However, the therapeutic strategy for CRC includes resection of distant metastases, and we can evaluate the local immune status in distant metastatic lesions. Our research group has previously shown that the density of TILs in the primary tumor of CRC correlated with the density of TILs in the hepatic metastasis removed by synchronous resection (38). In that study, we suggested that the evaluation of the local immunity of the primary tumor might be a substitute for the evaluation of the local immunity of the metastatic lesion (38). However, in cases of two-stage resection of a synchronous metastatic tumor or resection of a metachronous metastatic tumor, the immune status may change between the primary tumor and the metastatic tumor. This is due to the passage of time between resection of the primary tumor and that of the metastatic tumor or due to the treatments performed in that interval. In general, simultaneous resection is difficult in cases of pulmonary metastasis of CRC, so the immune status of the pulmonary metastasis of CRC may differ from that at the time of resection of the primary tumor of CRC. Therefore, the re-evaluation of the immune status of the host by evaluating the density of TILs in the metastatic tumor may be significant for the prediction of the prognosis. In the present study, the density of $\mathrm{CD} 3^{+}$TILs was significantly associated with the RFS after resection of pulmonary metastasis. Therefore, the re-evaluation of the density of TILs in pulmonary metastasis may lead to predict the prognosis after resection of pulmonary metastasis of CRC.

The density of CD8 ${ }^{+}$TILs, by contrast, was not shown to be associated with the RFS or the OS in the present study. However, this study was conducted in a small number of patients, so we considered the density of CD8 ${ }^{+}$TILs to nevertheless be an important immunological factor, as in previous reports.

Several limitations associated with the present study warrant mention. First, this study was retrospective and included a relatively small number of patients who had received resection of pulmonary metastasis at a single institution. Second, in the past 20 years, advances in surgical techniques and chemotherapy have changed the criteria of resection of pulmonary metastasis, the regimens of adjuvant chemotherapy after resection of pulmonary metastasis and the regimens of systemic chemotherapy at the time of recurrence after resection of pulmonary metastasis. Thus, the patients' background characteristics may have differed between older and newer cases. Therefore, a prospective study should be performed in the future.

In conclusion, the present study revealed that the immunological status of the host affected the therapeutic effects and the prognosis of patients with pulmonary metastasis of CRC, and immunological indices, such as the preoperative NLR and the density of TILs, may have prognostic significance as biomarkers for patients who undergo complete resection of pulmonary metastases of CRC.

\section{Conflicts of Interest}

The Authors declare that they have no competing interests in regard to this study.

\section{Authors' Contributions}

YO and MS designed the study. YO performed the statistical analysis and draft the manuscript. MS, HN, TF, YI and EW collected the clinical data and revised the manuscript critically. SK, $\mathrm{HT}, \mathrm{KM}, \mathrm{KH}$ and MO designed the study and critically reviewed the manuscript. All Authors read and approved the final manuscript.

\section{Acknowledgements}

This research received no specific grants from any funding agency in the public, commercial or not-for-profit sectors. The Authors thank Mr. Brian Quinn for providing medical writing services on behalf of Japan Medical Communication (JMC), Japan. 


\section{References}

1 Siegel R, Naishadham D and Jemal A: Cancer statistics, 2012. CA Cancer J Clin 62(1): 10-29, 2012. PMID: 22237781. DOI: $10.3322 /$ caac. 20138

2 Mitry E, Guiu B, Cosconea S, Jooste V, Faivre J and Bouvier AM: Epidemiology, management and prognosis of colorectal cancer with lung metastases: a 30-year population-based study. Gut 59(10): 1383-1388, 2010. PMID: 20732912. DOI: 10.1136/gut.2010.211557

3 Labianca R, Beretta GD, Kildani B, Milesi L, Merlin F, Mosconi S, Pessi MA, Prochilo T, Quadri A, Gatta G, de Braud F and Wils J: Colon cancer. Crit Rev Oncol Hematol 74(2): 106-133, 2010. PMID: 20138539. DOI: 10.1016/j.critrevonc.2010.01.010

4 Tampellini M, Ottone A, Bellini E, Alabiso I, Baratelli C, Bitossi R, Brizzi MP, Ferrero A, Sperti E, Leone F, Miraglia S, Forti L, Bertona E, Ardissone F, Berruti A, Alabiso O, Aglietta M and Scagliotti GV: The role of lung metastasis resection in improving outcome of colorectal cancer patients: results from a large retrospective study. Oncologist 17(11): 1430-1438, 2010. PMID: 22956535. DOI: 10.1634/theoncologist.2012-0142

5 Wang Z, Wang X, Yuan J, Zhang X, Zhou J, Lu M, Liu D, Li J and Shen L: Survival benefit of palliative local treatments and efficacy of different pharmacotherapies in colorectal cancer with lung metastasis: results from a large retrospective study. Clin Colorectal Cancer 17(2): e233-e255, 2018. PMID: 29305209. DOI: $10.1016 /$ j.clcc.2017.12.005

6 Zhang C, Tan Y and Xu H: Does adjuvant chemotherapy improve the prognosis of patients after resection of pulmonary metastasis from colorectal cancer? A systematic review and meta-analysis. Int J Colorectal Dis 34(10): 1661-1671, 2019. PMID: 31446479. DOI: 10.1007/s00384-019-03362-7

7 Kandioler D, Krömer E, Tüchler H, End A, Müller MR, Wolner $\mathrm{E}$ and Eckersberger F: Long-term results after repeated surgical removal of pulmonary metastases. Ann Thorac Surg 65(4): 909912, 1998. PMID: 9564899. DOI: 10.1016/s00034975(98)00019-8

8 Regnard JF, Grunenwald D, Spaggiari L, Girard P, Elias D, Ducreux M, Baldeyrou P and Levasseur P: Surgical treatment of hepatic and pulmonary metastases from colorectal cancers. Ann Thorac Surg 66(1): 214-218; discussion 218-219, 1998. PMID: 9692467. DOI: 10.1016/s0003-4975(98)00269-0

9 Okumura S, Kondo H, Tsuboi M, Nakayama H, Asamura H, Tsuchiya R and Naruke T: Pulmonary resection for metastatic colorectal cancer: experiences with 159 patients. J Thorac Cardiovasc Surg 112(4): 867-874, 1996. PMID: 8873711. DOI: 10.1016/S0022-5223(96)70085-5

10 Saito Y, Omiya H, Kohno K, Kobayashi T, Itoi K, Teramachi M, Sasaki M, Suzuki H, Takao H and Nakade M: Pulmonary metastasectomy for 165 patients with colorectal carcinoma: A prognostic assessment. J Thorac Cardiovasc Surg 124(5): 10071013, 2002. PMID: 12407386. DOI: 10.1067/mtc.2002.125165

11 Pfannschmidt J, Dienemann H and Hoffmann H: Surgical resection of pulmonary metastases from colorectal cancer: a systematic review of published series. Ann Thorac Surg 84(1): 324-338, 2007. PMID: 17588454. DOI: 10.1016/j.athoracsur. 2007.02.093

12 Nakajima J: Pulmonary metastasis: rationale for local treatments and techniques. Gen Thorac Cardiovasc Surg 58(9): 445-451, 2010. PMID: 20859722. DOI: 10.1007/s11748-010-0609-8
13 Iida T, Nomori H, Shiba M, Nakajima J, Okumura J, Horio H, Matsuguma H, Ikeda N, Yoshino I, Ozeki Y, Takagi K, Goya T, Kawamura M, Hamada C and Kobayashi K; Metastatic Lung Tumor Study Group of Japan: Prognostic factors after pulmonary metastasectomy for colorectal cancer and rationale for determining surgical indications: a retrospective analysis. Ann Surg 257(6): 1059-1064, 2013. PMID: 23001087. DOI: 10.1097/ SLA.0b013e31826eda3b

14 Kanemitsu Y, Kato T, Hirai T and Yasui K. Preoperative probability model for predicting overall survival after resection of pulmonary metastases from colorectal cancer. Br J Surg 91(1): 112-120, 2004. PMID: 14716804. DOI: 10.1002/bjs.4370

15 Okumura T, Boku N, Hishida T, Ohde Y, Sakao Y, Yoshiya K, Higashiyama M, Hyodo I, Mori K and Kondo H: Surgical outcome and prognostic stratification for pulmonary metastasis from colorectal cancer. Ann Thorac Surg 104(3): 979-987, 2017. PMID: 28577846. DOI: 10.1016/j .athoracsur.2017.03.021

16 Lin BR, Chang TC, Lee YC, Lee PH, Chang KJ and Liang JT: Pulmonary resection for colorectal cancer metastases: duration between cancer onset and lung metastasis as an important prognostic factor. Ann Surg Oncol 16(4): 1026-1032, 2009. PMID: 19184237 . DOI: $10.1245 / \mathrm{s} 10434-008-0286-3$

17 Hirosawa T, Itabashi M, Ohnuki T, Yamaguchi N, Sugihara K, Kameoka S; Japanese Society for Cancer of the Colon and Rectum (JSCCR) Study Group for Pulmonary Metastases from Colorectal Cancer: Prognostic factors in patients undergoing complete resection of pulmonary metastases of colorectal cancer: a multi-institutional cumulative follow-up study. Surg Today 43(5): 494-499, 2013. PMID: 23085967. DOI: 10.1007/s00595012-0373-8

18 Gonzalez M and Gervaz P: Risk factors for survial after lung metastasectomy in colorectal cancer patients: A systematic review and meta-analysis. Future Oncol 20(2): 572-579, 2015. PMID: 25662325. DOI: 10.2217/fon.14.259

19 Watanabe K, Nagai K, Kobayashi A, Sugito M and Saito N: Factors influencing survival after complete resection of pulmonary metastases from colorectal cancer. Br J Surg 96(9): 1058-1065, 2009. PMID: 19672932. DOI: 10.1002/bjs.6682

20 Brierley JD, Gospodarowicz MK and Wittekind C (eds.): TNM Classification of Malignant Tumours, $8^{\text {th }}$ edition. New York, John Wiley \& Sons, Ltd., 2017.

21 Yaguchi T, Sumimoto H, Kudo-Saito C, Tsukamoto N, Ueda R, Iwata-Kajihara T, Nishio H, Kawamura N and Kawakami Y: The mechanisms of cancer immunoescape and development of overcoming strategies. Int J Hematol 93(3): 294-300, 2011. PMID: 21374075. DOI: 10.1007/s12185-011-0799-6

22 Fridman WH, Pagès F, Sautès-Fridman C and Galon J: The immune contexture in human tumours: Impact on clinical outcome. Nat Rev Cancer 12(4): 298-306, 2012. PMID: 22419253. DOI: $10.1038 / \mathrm{nrc} 3245$

23 Chiang SF, Hung HY, Tang R, Changchien CR, Chen JS, You YT, Chiang JM and Lin JR: Can neutrophil-to-lymphocyte ratio predict the survival of colorectal cancer patients who have received curative surgery electively? Int J Colorectal Dis 27(10): 1347-1357, 2012. PMID: 22460305. DOI: 10.1007/s00384-012$1459-\mathrm{x}$

24 Mallappa S, Sinha A, Gupta S and Chadwick SJ: Preoperative neutrophil to lymphocyte ratio $>5$ is a prognostic factor for recurrent colorectal cancer. Colorectal Dis 15(3): 323-328, 2013. PMID: 22958479. DOI: 10.1111/codi.12008 
25 Garcea G, Ladwa N, Neal CP, Metcalfe MS, Dennison AR and Berry DP: Preoperative neutrophil-to-lymphocyte ratio (NLR) is associated with reduced disease-free survival following curative resection of pancreatic adenocarcinoma. World J Surg 35(4): 868872, 2011. PMID: 21312035. DOI: 10.1007/s00268-011-0984-z

26 Shimada H, Takiguchi N, Kainuma O, Soda H, Ikeda A, Cho A, Miyazaki A, Gunji H, Yamamoto H and Nagata M: High preoperative neutrophil-lymphocyte ratio predicts poor survival in patients with gastric cancer. Gastric Cancer 13(3): 170-176, 2010. PMID: 20820986. DOI: 10.1007/s10120-010-0554-3

27 Hendry S, Salgado R, Gevaert T, Russell PA, John T, Thapa B, Christie M, van de Vijver K, et al.: Assessing tumor-infiltrating lymphocytes in solid tumors: A practical review for pathologists and proposal for a standardized method from the international immunooncology biomarkers working group: Part 1: Assessing the host immune response, tils in invasive breast carcinoma and ductal carcinoma in situ, metastatic tumor deposits and areas for further research. Adv Anat Pathol 24(5): 235-251, 2017. PMID: 28777142. DOI: 10.1097/PAP.0000000000000162

28 Hendry S, Salgado R, Gevaert T, Russell PA, John T, Thapa B, Christie M, van de Vijver K, et al.: Assessing tumor-infiltrating lymphocytes in solid tumors: A practical review for pathologists and proposal for a standardized method from the international immuno-oncology biomarkers working group: Part 2: TILs in melanoma, gastrointestinal tract carcinomas, non-small cell lung carcinoma and mesothelioma, endometrial and ovarian carcinomas, squamous cell carcinoma of the head and neck, genitourinary carcinomas, and primary brain tumors. Adv Anat Pathol 24(6): 311-335, 2017. PMID: 28777143. DOI: 10.1097/ PAP.0000000000000161

29 Maeda K, Shibutani M, Otani H, Nagahara H, Sugano K, Ikeya T, Amano R, Kimura K, Sakurai K, Kubo N, Muguruma K, Tanaka $\mathrm{H}$, Inoue $\mathrm{T}$ and Hirakawa $\mathrm{K}$. Prognostic value of preoperative inflammation-based prognostic scores in patients with stage IV colorectal cancer who undergo palliative resection of asymptomatic primary tumors. Anticancer Res 33(12): 55675573, 2013. PMID: 24324099.

30 Terzić J, Grivennikov S, Karin E and Karin M: Inflammation and colon cancer. Gastroenterology 138(6): 2101-2114, 2010. PMID: 20420949. DOI: 10.1053/j.gastro.2010.01.058

31 Lin EY and Pollard JW: Role of infiltrated leucocytes in tumour growth and spread. Br J Cancer 90(11): 2053-2058, 2004. PMID: 15164120. DOI: $10.1038 /$ sj.bjc. 6601705
32 An X, Ding PR, Li YH, Wang FH, Shi YX, Wang ZQ, He YJ, $\mathrm{Xu}$ RH and Jiang WQ: Elevated neutrophil to lymphocyte ratio predicts survival in advanced pancreatic cancer. Biomarkers 15(6): 516-522, 2010. PMID: 20602543. DOI: 10.3109/ 1354750X.2010.491557

33 Kishi Y, Kopetz S, Chun YS, Palavecino M, Abdalla EK and Vauthey JN: Blood neutrophil-to-lymphocyte ratio predicts survival in patients with colorectal liver metastases treated with systemic chemotherapy. Ann Surg Oncol 16(3): 614-622, 2009. PMID: 19130139. DOI: 10.1245/s10434-008-0267-6

34 Roxburgh CS and McMillan DC: Role of systemic inflammatory response in predicting survival in patients with primary operable cancer. Future Oncol 6(1): 149-163, 2010. PMID: 20021215. DOI: $10.2217 /$ fon.09.136

35 Shibutani M, Maeda K, Nagahara H, Noda E, Ohtani H, Nishiguchi Y and Hirakawa K: A high preoperative neutrophilto-lymphocyte ratio is associated with poor survival in patients with colorectal cancer. Anticancer Res 33(8): 3291-3294, 2013. PMID: 23898094

36 Galon J, Costes A, Sanchez-Cabo F, Kirilovsky A, Mlecnik B, Lagorce-Pagès $\mathrm{C}$, Tosolini $\mathrm{M}$, Camus $\mathrm{M}$, Berger $\mathrm{A}$, Wind $\mathrm{P}$, Zinzindohoué F, Bruneval P, Cugnenc PH, Trajanoski Z, Fridman WH and Pagès F: Type, density, and location of immune cells within human colorectal tumors predict clinical outcome. J Science 313(5795): 1960-1964, 2006. PMID: 17008531. DOI: $10.1126 /$ science. 1129139

37 Pagès F, Mlecnik B, Marliot F, Bindea G, Ou FS, Bifulco C, Lugli A, Zlobec I, Rau TT, Berger MD et al: International validation of the consensus Immunoscore for the classification of colon cancer: a prognostic and accuracy study. Lancet 391(10135): 2128-2139, 2018. PMID: 29754777. DOI: 10.1016/ S0140-6736(18)30789-X

38 Shibutani M, Maeda K, Nagahara H, Fukuoka T, Matsutani S, Kashiwagi S, Tanaka H, Hirakawa $\mathrm{K}$ and Ohira M: A comparison of the local immune status between the primary and metastatic tumor in colorectal cancer: a retrospective study. BMC Cancer 18(1): 371, 2018. PMID: 29614981. DOI: $10.1186 / \mathrm{s} 12885-018-4276-\mathrm{y}$

Received November 13, 2020

Revised November 27, 2020

Accepted November 28, 2020 